LUDWIK ZABROCKI

\title{
Summer Foreign Language Courses for Students and University Lectors in Poland
}

It is by now a generally accepted fact that a foreign language is best taught by the teacher who is a native speaker. It is so because a large number of university lectors as well as secondary school teachers do not speak the foreign language correctly, i.e. as their second native language.

In such a situation language laboratories should be resorted to as a help. It has to be borne in mind, however, that a laboratory is only a substitute for a native speaker. Moreover the present technical conditions of the laboratories (half-soundproof booths, ear-phone-playback system) as well as the methods being used cannot yield the desired result. There would remain holiday visits abroad. Since mass departures of young people abroad are not possible at the moment, we must have recoursed to another substitute. Participating in vacation courses has been made obligatory in our country. Students participate in a course only once during their studies. Lectors have the opportunity to attend the above-mentioned courses almost every year. They are arranged for teachers of English, French, German and Russian and they last for three weeks. Five hours of work a day are divided into three hours of classes and two hours of lecture in literature and cultural problems. Lectures are delivered and classes are conducted exclusively by professors and lecturers from abroad.

The main objective of the courses is contact with the native speakers of the language in question. We hold the view that a 3 -week contact with the voices of native speakers ought to contribute to the correction and strengthening of the structural and phonic matrix of the given foreign language. Special phonetic drills aim to further increase the automatic correction of the matrix. The exercises comprise vocabulary and phraseology of everyday language. At the lectures, on the other hand, the course members meet with the language of letters.

In order to enable our students to keep in touch all day with the given foreign language, the institution of mentors has been introduced. The planned ratio is one mentor to seven students. Students from abroad live in the same rooms and spend their leisure in the company of our students.

At the courses there were also demonstrated the methods of foreign language teaching used in the respective native countries of the visiting professors. In the English section work in a language laboratory has been demonstrated for the last two years. It is being demonstrated by Americans.

The effects of the language course which have been arranged so far, and more than 10 have already been held, can be estimated as satisfactory. Considerable improvement of pronunciation was obtained in students, even in those who, for some reason or other, showed no interest in the course. Also the matrices of dif- 
ferent structures improved. In lectors the improvement in pronunciation has to be regarded as a certain correction of secondary interference. This means that the lector's pronunciation can be brought by exercises to its primary state as regards the reproduction of the phonic matrix. That primary state, however, i.e. the state obtained by the lector while learning the language in his youth, cannot be improved upon. In this case the degree of correction also depended on different factors. The essential one was the age parameter. It seems that doing remedial exercises in phonetics for lectors aged over forty will not pay, and after the age of fifty it is wholly useless.

Exercises in phraseology and vocabulary, on the other hand, yield concrete results also in the case of elderly lectors, i.e. aged forty and over.

The courses ought, in my opinion, to be accordingly reorganized. In future objective tests should also be made as to the results obtained in improving the reproductive matrices of different kinds. For that purpose, however, appropriate electronic equipment would be necessary. It has to be stated here, however, that it is also possible to establish auditively, fairly easily, the differences in pronunciation before and after the correction. It suffices only to record, for the purpose of testing, the pronunciations of a certain number of students and lectors.

As an essential stipulation it should be put forward that in future one mentor should be planned to each room. The mentors must also be appropriately selected. A mentor ought to draw, of his own accord, Polish students into conversation. He must be interested in the linguistic correction of the members of the course. The mentors must accordingly be trained to some extent in modern methods of teaching and possess certain personal qualities. They cannot be e.g. taciturn, reticent etc. persons.

The course itself ought to last four weeks. Three weeks is decidely not enough. Each language section ought to be situated in a separate building or the courses held in different localities. Lecturers from abroad ought to be acquainted beforehand with the methods of teaching in Poland. 